\title{
Prevalence of colonic polyps among patients with Acromegaly
}

\author{
S.Pathmanathan ${ }^{1}$, Noel.P.Somasundaram ${ }^{1}$, N.M.M. Nawarathne ${ }^{2}$ \\ ${ }^{1}$ Endocrinology unit, National Hospital of Sri Lanka, Colombo \\ 2 Gastroenterology unit, National Hospital of Sri Lanka, Colombo
}

\section{Abstract}

Background: Patients with acromegaly are reported to have a higher prevalence of colorectal adenoma, which is a premalignant condition. It has been recommended that patients with acromegaly should undergo colonoscopic surveillance to detect these lesions early.

Aims and Objectives: Our objective was to evaluate the prevalence of colonic polyps in patients with acromegaly.

Materials: This was a descriptive cross-sectional study conducted in the Endocrinology and Pituitary clinics at National Hospital of Sri Lanka between January 2012 and June 2013. From a total of 72 patients with acromegaly, 33 patients (13 males and 20 females), who underwent colonoscopy were enrolled for analysis. Age group of this sample was 29 to 71 years. None of these patients had previous or family history of colonic neoplasm or colonic surgery.

Results: The mean age of the patients at diagnosis was 40.12 ( $\mathrm{SD} \pm 11.9$ ) years and average lag time between symptomatology and diagnosis of acromegaly in these patients were 3.5 (SD \pm 2.8 ) years. The basal mean plasma Growth hormone was $57.91 \mathrm{mU} / \mathrm{L}(\mathrm{SD} \pm 53.74)$ and on imaging $28(84.84 \%)$ had tumour of grade II or above. Colonoscopic examination was complete up to the cecum in 23 patients $(69.69 \%)$, to the splenic flexure in eight patients $(24.24 \%)$ and to hepatic flexure in the remaining two patients $(6.06 \%)$. Five patients $(15 \%)$ with acromegaly had polyps in their colonoscopy in which two of them had tubular adenoma with low grade dysplasia. The group of acromegalic patients with and without polyps did not differ significantly in age $39.8 \pm 13.3$ years vs $39.71 \pm 11.34$ years, $(\mathrm{p}=0.326)$, in duration of disease $2.8 \pm 2.0$ years vs $3.6 \pm 3.0$ years, $(\mathrm{p}=0.544)$ or in circulating basal GH levels $(77.13 \pm 64.91 \mathrm{mU} / \mathrm{L}$ vs $42.61 \pm 42.70$ $\mathrm{mU} / \mathrm{L}, \mathrm{p}=0.134)$. Diabetes did not influence the prevalence of colonic polyps in acromegaly (Chi-Squared test; $\mathrm{p}=0.478)$. Having polyps was statistically significantly higher among male sex than female sex $(\mathrm{p}<0.05)$, but a conclusion cannot be made due to small sample size. Four out of the 5 acromegalic patients who had polyps had active disease when the colonoscopy was performed.Conclusion: Despite lower prevalence of colonic polyps (15\%) compared to studies from the west, we still found premalignant lesions in 2 patients $(6.06 \%)$. Therefore, we suggest that acromegalic patients should undergo screening colonoscopy.

Key words: Acromegaly, colonic polyps, screening colonoscopy, Sri Lanka

Received: $5^{\text {th }}$ July 2018

Accepted with revision: 23 $3^{\text {rd }}$ July 2018

Published: $31^{\text {st }}$ Aug 2018

Correspondence email: psivatharshya@gmail.com

https://orcid.org/0000-0002-2510-3642

This is an open-access article distributed under the terms of the Creative Commons Attribution License, which permits unrestricted use, distribution, and reproduction in any medium, provided the original author and source are credited (CC BY 4.0) 


\section{Introduction}

Acromegaly is known to be associated with an increased risk of developing colonic tumors which could be sometimes premalignant. Several studies on prevalence of colorectal polyps in patients with acromegaly from western world, report widely between $23 \%$ and $53 \%$ (1-5). It has been recommended that patients with acromegaly should undergo colonoscopic surveillance from the age of 40 years onwards and thereafter regularly every two to three years if an adenoma is found (6)

Acromegaly, a disorder of growth hormone (GH) hyper secretion is usually caused by pituitary somatotropinoma. Acromegaly induces the increased generation of insulinlike growth factor-1 (IGF-1) which may be involved in the process of development of colonic polyps (1-5). Both GH and IGF-1 are known to promote cellular growth and proliferation and proto-oncogene expression (6). Studies have shown $\mathrm{GH}$ induced expression of oncogenes in many mammalian tissues and also has confirmed the presence of IGF-1 receptors on colonic tissue (7). This descriptive study was undertaken to define the prevalence of colorectal adenomas among patients with acromegaly following Endocrine and pituitary clinics at National Hospital of Sri Lanka.

\section{Objectives}

\section{General Objective}

To describe the prevalence of colonic polyps in patients with acromegaly and associated factors.

\section{Specific Objectives}

To describe the prevalence of colonic polyps in patients with acromegaly. To describe the associated factors to colonic polyp.

Methodology

\section{Study design, Study setting and Study population}

This was a descriptive cross-sectional study conducted in the Endocrinology and Pituitary clinics at National Hospital of Sri Lanka between January 2012 and June 2013. From a total of 72 patients with acromegaly, 33 patients (13 males and 20 females), were enrolled for the study. Age group of this sample was 29 to 71 years.

The diagnosis of acromegaly was made on clinical grounds, supported by increased basal growth hormone $(\mathrm{GH})$ levels and non-suppressible plasma $\mathrm{GH}$ (normal: $<1 \mathrm{mU} / \mathrm{L}$ ) after a $75 \mathrm{~g}$ oral glucose load.

A data sheet was used for data collection and data gathered from clinic records with regard to the following aspects. Age on presentation, sex, basal circulating plasma GH levels, non-suppressible plasma GH after $75 \mathrm{~g}$ oral glucose load, details of the pituitary tumour and duration of $\mathrm{GH}$ exposure were recorded. Duration of GH exposure was based on the lag time between symptomatology and diagnosis of acromegaly. All patients underwent MRI scan of the pituitary as the primary mode of imaging. Pituitary adenomas were classified based on Hardy's classifications. (Table 1).

Diabetes mellitus associated with acromegaly was also taken into account. Patients who did not consent for the colonoscopy and in patients colonoscopy procedure was abandoned due to poor patient cooperation and patients with a family history of colonic neoplasms were excluded from the study. Patients who underwent only flexible sigmoidoscopy were also excluded from analysis. None of the patients had inflammatory bowel disease.

The patients who consented for the colonoscopy were referred for a full-length colonoscopy. Colonoscopies were performed by consultant gastroenterologist using a $165 \mathrm{~cm}$ length colonoscope (Olympus, Tokyo, Japan). Bowel preparations were done using standard preparation with klean prep (Macrogol 3350, Sodium sulphate anhydrous, Sodium bicarbonate, Sodium chloride and Potassium chloride). All lesions were removed and these were subjected to histological examination and polyps were classified as adenomas, adenocarcinomas and hyperplastic polyps. 


\section{Table 1: Neuroanatomical classification of pituitary adenomas (Based on Hardy, 1969.)}

\begin{tabular}{llll} 
Grade & Size & Location & Bony changes \\
\hline I & $<10 \mathrm{~mm}$ & Intrapituitary & None \\
II & $>10 \mathrm{~mm}$ & Intrasellar or suprasellar expansion, no invasion & Sellar expansion \\
III & Any & Intrasellar or suprasellar expansion, local invasion & Sellar erosion \\
IV & $>10 \mathrm{~mm}$ & Suprasellar expansion, invasion of extrasellar structures & Bone invasion
\end{tabular}

\section{Statistical analysis}

Analysis of data was carried out using SPSS 20 version. Mean values and standard deviation were estimated for each continuous variable, such as age, duration on presentation, basal GH levels and duration of therapy while proportions were estimated for categorical variables. Chi square value was used to compare proportions while Student's t test was used to compare continuous variables. $\mathrm{p}<0.05$ was considered as the level of significance.

\section{Results}

The mean age of the patients at diagnosis was 40.12 $(\mathrm{SD} \pm 11.9)$ years and average lag time between symptomatology and diagnosis of acromegaly in these patients were $3.5(\mathrm{SD} \pm 2.8$ ) years. The basal mean plasma $\mathrm{GH}$ was $57.91 \mathrm{mU} / \mathrm{L}(\mathrm{SD} \pm 53.74)$ and mean plasma $\mathrm{GH}$ after $75 \mathrm{~g}$ oral glucose load was $51.22 \mathrm{mU} / \mathrm{L}$ (SD \pm 45.47 ). On imaging, four patients $(12.12 \%)$ had Grade I tumour while $28(84.84 \%)$ had Grade II tumour and above. One patient $(3.03 \%)$ had normal pituitary MRI.(Table 2).

Colonoscopic examination was complete to the caecum in 23 patients $(69.69 \%)$, to the splenic flexure in eight patients $(24.24 \%)$ and to hepatic flexure in the remaining two patients $(6.06 \%)$. Colonoscopy findings were abnormal in $11(33.33 \%)$ patients.

The findings on the colonoscopy were classified as follows.(Table 3).

Five patients $(15 \%)$ with acromegaly had polyps in their colonoscopy. Three patients had the polyps in the transverse colon while one patient had it closer to the hepatic flexure and another patient had polyps in the rectum. On histopathology two of these polyps were classified as hyperplastic polyps. Two were classified as tubular adenoma with low grade dysplasia. One polyp which was removed completely was lost during the procedure. None of the patients had colonic carcinoma. The group of acromegalic patients with and without polyps did not differ significantly in age $39.8 \pm 13.3$ years vs 39.71 \pm 11.34 years, $(\mathrm{p}=0.326)$, in duration of disease $2.8 \pm 2.0$ years vs 3.6 \pm 3.0 years, $(\mathrm{p}=0.544)$ or in circulating basal $\mathrm{GH}$ levels $(77.13 \pm 64.91 \mathrm{mU} / \mathrm{L}$ vs $42.61 \pm 42.70 \mathrm{mU} / \mathrm{L}, \mathrm{p}=$ 0.134). Diabetes did not influence the prevalence of colonic polyps in acromegaly. Three out of the 15 diabetic acromegalic patients $(20 \%)$ and two out of 18 nondiabetic acromegalic patients $(11.1 \%)$ had polyps that was not statistically significant $(p=0.585)$. Having polyps was statistically significantly higher among male sex than female sex $(p<0.05)$ but a conclusion cannot be made due to poor sample size. The detailed results are presented in table- 4 and figure-1. Four out of the 5 acromegalic patients who had polyps had active disease when the colonoscopy was performed. (Table 5). 


\section{Table 2: Age category and diagnosis in the sample patients}

\begin{tabular}{lllll} 
& & Males & Females & Total \\
\hline Age Category & $<40$ years & 06 & 09 & $15(45.4 \%)$ \\
Size of the tumour & $>40$ years & 07 & 11 & $18(54.5 \%)$ \\
& Grade I & 01 & 03 & $4(12.12 \%)$ \\
& Grade II and Above & 12 & 16 & $28(84.84 \%)$ \\
& Normal MRI & 00 & 01 & $01(3.03 \%)$
\end{tabular}

Table 3: Findings of the colonoscopy examination

\begin{tabular}{lllll} 
Findings & & Males & Females & Total \\
\hline Abnormal & Presence of polyps & 03 & 02 & $05(15.15 \%)$ \\
& Presence of Diverticula & 00 & 03 & $03(9.09 \%)$ \\
& GI Haemorrhoids & 02 & 00 & $02(6.06 \%)$ \\
& GI Haemorrhoids with abnormal & 01 & 00 & $01(3.03 \%)$ \\
Normal & mucosa & & 07 & 15 \\
& & & $22(66.66 \%)$
\end{tabular}

Table -4: Group Statistics

\begin{tabular}{llllll} 
& Polyp Status & Number & Mean & SD & p value \\
\hline Age & No & 28 & 48.86 & 10.459 & $\mathrm{p}=0.761$ \\
& Yes & 5 & 47.20 & 14.805 & \\
Basal GH level & No & 28 & 42.61 & 42.708 & $\mathrm{p}=0.134$ \\
& Yes & 5 & 77.13 & 64.911 & \\
Duration of the & No & 28 & 3.6786 & 3.06175 & $\mathrm{p}=0.544$ \\
disease & Yes & 5 & 2.8000 & 2.04939 &
\end{tabular}




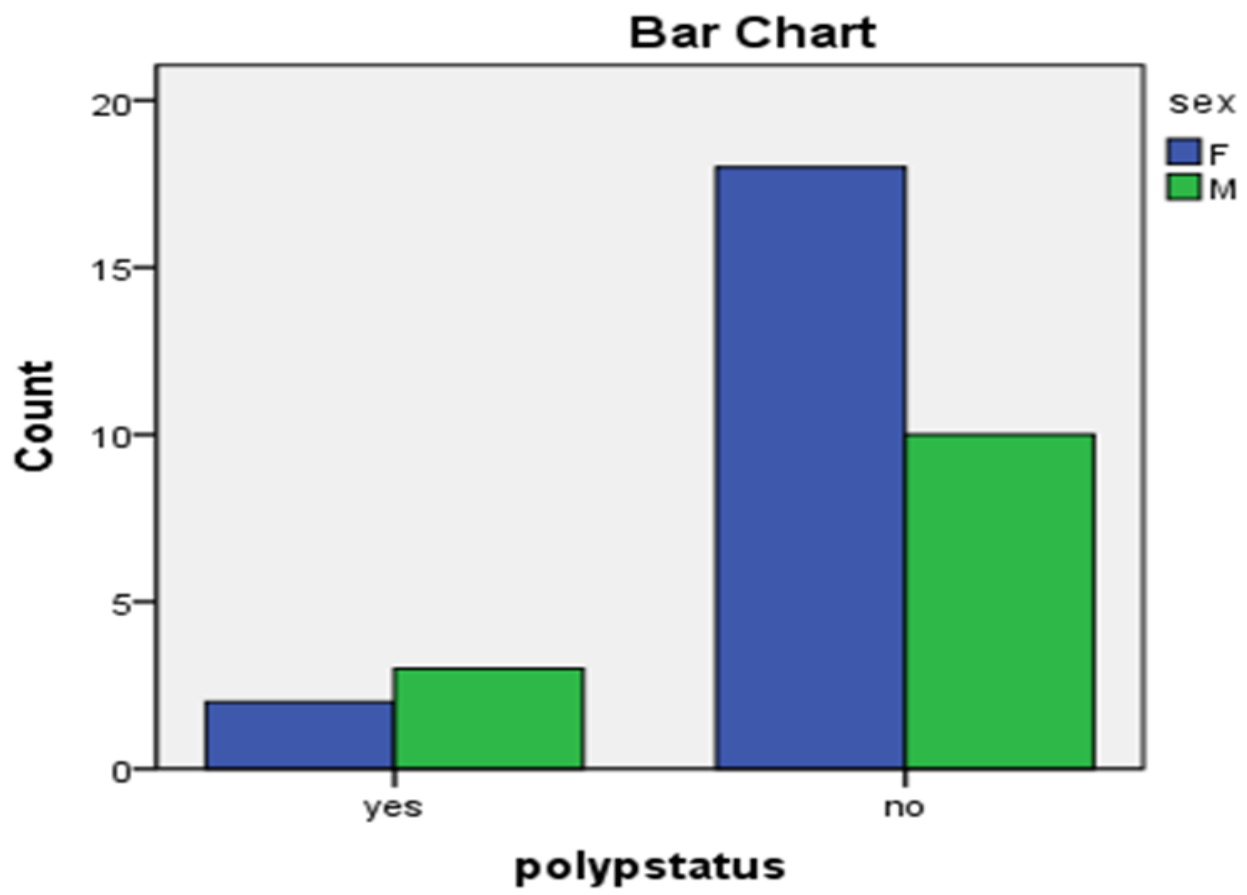

Figure 1: Bar chart depicts sex vs presence of polyps.

\section{Table: 5 Status of the disease at the time of colonoscopy}

\begin{tabular}{llll} 
Colonoscopy findings & Cured & Uncured & Total \\
\hline Abnormal & 01 & 04 & 05 \\
Polyps & 03 & 00 & 03 \\
Diverticulae & 01 & 01 & 02 \\
GI Hemorrhoids & 01 & 00 & 01 \\
GI Hemorrhoids with abnormal mucosa & 06 & 16 & 22 \\
Normal & 12 & 21 & 33 \\
Total & & &
\end{tabular}

\section{Discussion}

Colorectal neoplasms are well known complications of acromegaly and these patients are at increased risk of developing colorectal cancer. Several studies on prevalence of colorectal polyps in patients with acromegaly from western world, report widely between 23\% and 53\% (1-5). Nevertheless at least two studies from the West failed to show increased prevalence of colonic neoplasia among acromegalics $(8,9)$. It has also been suggested that the risk of colorectal cancers may be dependent on the geographic and ethnic origin of the patients. Data on the prevalence of colorectal neoplasms in Asian patients with acromegaly are limited. A recent study from Japan (10) showed an increased risk of colorectal neoplasms, especially colorectal adenocarcinomas (a prevalence of $38.6 \%$ for hyperplastic polyps, $31.6 \%$ for adenomas and $5.3 \%$ for adenocarcinomas) whereas a study from India (11) failed to demonstrate the high prevalence rate of colonic neoplasia among patients with acromegaly. The discrepancy in the 
data may be related to the differences among the study populations and the differences in methodology in different studies. Our study shows a prevalence of $15 \%$, a frequency closer to the findings of at least 2 studies Brunner et al (12) $(14 \%)$ and Larijani et a (13) (13\%). We found premalignant lesions in 2 patients $(6.06 \%)$.

Age is an important factor that could influence the prevalence rates of colonic adenomas in acromegalic patients. Our study failed to show an association between age and prevalence of colonic polyps which is in contrast with the studies by Jenkins et al (5) and Renehan et al (9). They observed that the prevalence rates increased with each decade. The mean age of patients with acromegaly in different studies on colonic neoplasia has shown wide variation and this could influence the prevalence rates of polyps in the published studies.

Our study shows the prevalence of polyps was significantly increased in male acromegalic patients compared to female acromegalic patients. $(\mathrm{p}<0.05)$. Both Brunner et al $(12)$ and Delhougne et al (1) have published similar results. Nevertheless, we are unable to arrive at a conclusion from our study due to poor sample size and this correlation may be established with a larger sample size.

The duration of disease, basal GH levels and glycemic status did not differ significantly in acromegalic patients with and without polyps in the present study. Similar results were also observed by Bhansali et al (11) from India although in contrast to Matano et al (14) who suggest that high serum GH levels may be associated with the high presence of colonic polyps in acromegaly patients. Similarly, studies which looked for any association between IGF1 levels and the presence of colonic polyps also showed conflicting results. Dworakowska et a (15) and Dutta et al (16) showed elevated IGF1 levels are associated with high prevalence of colonic polyps whereas Larijani et al (13) and Jenkins et al (5) failed to show an association between IGF1 and presence of colonic polyps.
Wassenaar et al (17) showed that acromegaly is also associated with an increased prevalence of colonic diverticula. In their study colonic diverticula were present in $37 \%$ of patients with acromegaly. Interestingly $9 \%$ of our study population too had colonic diverticula. Although it has been suggested that this observation is due to the irreversible effect of $\mathrm{GH}$ and/or IGF-I on the collagen in the colon we need further studies on this finding.

Studies of acromegalic patients show colonoscopic examination may be technically difficult to be performed due to the increased bowel length and the loop complexity $(6,9)$. Moreover; more vigorous colonic lavage (twice the "standard" amount of the osmotic purgative Klean-Prep) may be needed for satisfactory bowel preparation before colonoscopy (6). These factors play an important role in a successful colonoscopic examination which in turn could affect the prevalence rate of the polyps. We used the standard bowel preparation in our study, but further studies following vigorous colonic lavage need to be carried out in future to find out the true prevalence.

Small sample size was the main limitation of our study; however, this does not invalidate our findings and prospective studies with sufficient power are required to investigate the true prevalence of colonic polyps in patients with acromegaly.

\section{Conclusion}

Despite lower prevalence of colonic polyps (15\%) compared to studies from west we still found premalignant lesions in 2 patients $(6.06 \%)$. Therefore, we suggest that acromegalic patients should undergo screening colonoscopy.

\section{References}

1. Delhougne B, Deneux C, Abstract R et al. The prevalence of colonic polyps in acromegaly: a colonoscopic and pathologic study in 103 patients. The Journal of Clinical Endocrinology and Metabolism.1995; 80: 3223-6.

2. Klein I, Parveen G, Gavaler JS, Vanthiel DH. Colonic polyps in patients with acromegaly. Annals of Internal Medicine 1982; 97: 27-30.

3. Ezzat S, Strom C, Melmed S. Colon polyps in acromegaly. Annals of Internal Medicine 1991; 224: 754-5.

4. Terzolo M, Tappero G, Borretta G, Asnaghi G, Pia A,Reimondo G, et al. High prevalence of colonic polyps in patients with acromegaly. Influence of sex and age. Archives of Internal Medicine. 1994; 154: 1272 - 1276.

5. Jenkins PJ, Fairclough PD, Richards T et al. Acromegaly,colonic polyps and carcinoma. Clinical Endocrinology(Oxford). 1997; 47:17-22.

6. Jenkins PJ, Besser GM. Fairclough P D. Colorectal neoplasia in acromegaly. Gut 1999; 44: 585-7.

7. Murphy LJ, Bill GI, Friesen HG. Growth hormone stimulates sequential induction of $c$-myc and insulin-like growth factor 1 expression in vivo. Endocrinology 1987;120: 1806-12.

8. Ladas SD, Thalassinos NC, Ioannides G, Raptis SA.Does acromegaly really predispose to an increased prevalence of gastrointestinal tumours? Clinical Endocrinology(Oxford). 1994;41: 597-601. 
9. Renehan AG, Bhaskar P, Painter JE et al. The prevalence and characteristics of colorectal neoplasia in acromegaly. The Journal of Clinical Endocrinology and Metabolism. 2000; 85: 3417-24.

10. Yamamoto M, Fukuoka H, Iguchi G, Matsumoto R, Takahashi M, Nishizawa H, Suda K, Bando H, Takahashi Y. The prevalence and associated factors of colorectal neoplasms in acromegaly: a single center based study. Pituitary. 2014 Jun 20 [Epub ahead of print]

11. Bhansali A ${ }^{1}$, Kochhar R, Chawla YK, Reddy S, Dash RJ Prevalence of colonic polyps is not increased in patients with acromegaly: analysis of 60 patients from India. Journal of Gastroenterology and Hepatology. 2004 ;19(3):266-9.

12. Brunner JE, Johnson CC, Zafar S, Peterson EL, Brunner JF, Mellinger RC. Colon cancer and polyps in acromegaly: increased risk associated with family history of colon cancer. Clinical Endocrinology (Oxford). 1990; 32:65 - 71.

13. Larijani B, Aliannejad R, Khaleghnejad-Tabari N, Baradar-Jalili R, Ansari R, Tavangar SM, Bandarian F. The prevalence of polyp in colon of patients with acromegaly. Archives of Iranian Medicine. 2007 ;10(2):236-8.

14. Matano $\mathrm{Y}^{1}$, Okada T, Suzuki A, Yoneda T, Takeda Y, Mabuchi H. Risk of colorectal neoplasm in patients with acromegaly and its relationship with serum growth hormone levels. The American Journal of Gastroenterology. 2005 ;100(5):1154-60.

15. Dworakowska D11, Gueorguiev M, Kelly P, Monson JP, Besser GM, Chew SL, Akker SA, Drake WM, Fairclough PD, Grossman AB, Jenkins PJ Repeated colonoscopic screening of patients with acromegaly: 15-year experience identifies those at risk of newcolonic neoplasia and allows for effective screening guidelines. European Journal of Endocrinology. 2010 ;163(1):21-8.

16. Dutta P, Bhansali A, Vaiphei K, Dutta U, Ravi Kumar P, Masoodi S, Mukherjee KK, Varma A, Kochhar R.Colonic neoplasia in acromegaly: increased proliferation or deceased apoptosis? Pituitary. 2012 ;15(2):166-73.

17. Wassenaar MJ, Cazemier M, Biermasz NR, Pereira AM, Roelfsema F, Smit JW, Hommes DW, Felt-Bersma RJ, Romijn JA. Acromegaly is associated with an increased prevalence of colonic diverticula: a case-control study. The Journal of Clinical Endocrinology and Metabolism.2010 ;95(5):2073-9. 